\title{
What the Laboratory Rat has Taught us About Social Play Behavior: Role in Behavioral Development and Neural Mechanisms
}

\author{
Louk J.M.J. Vanderschuren and Viviana Trezza
}

\begin{abstract}
Social play behavior is the most vigorous and characteristic form of social interaction displayed by developing mammals. The laboratory rat is an ideal species to study this behavior, since it shows ample social play that can be easily recognized and quantified. In this chapter, we will first briefly describe the structure of social play behavior in rats. Next, we will discuss studies that used social isolation rearing during the period in life when social play is most abundant to investigate the developmental functions of social play behavior in rats, focusing on the consequences of play deprivation on social, cognitive, emotional, and sensorimotor development. Last, we will discuss the neural substrates of social play behavior in rats, with emphasis on the limbic corticostriatal circuits that underlie emotions and their influence on behavior.
\end{abstract}

Keywords Social play behavior - Development - Social behavior - Cognition • Emotion • Prefrontal cortex • Nucleus accumbens • Amygdala

L. J.M.J.Vanderschuren ( $\bowtie)$

Department of Animals in Science and Society, Division of Behavioural Neuroscience,

Utrecht University, Yalelaan 2, 3584 CM Utrecht, The Netherlands

e-mail: 1.j.m.j.vanderschuren@uu.nl

L. J.M.J.Vanderschuren

Department of Translational Neuroscience, Brain Center Rudolf Magnus,

University Medical Center Utrecht, Utrecht, The Netherlands

V. Trezza

Department of Science, Section of Biomedical Sciences and Technologies,

University Roma Tre, Rome, Italy 


\section{Contents}

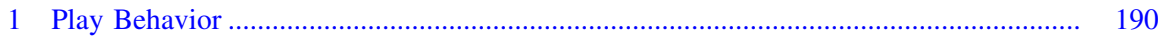

2 Social Play Behavior in Rats ........................................................................ 191

3 The Developmental Functions of Social Play Behavior.................................................. 193

3.1 Social Play Behavior and Social Development......................................................... 193

3.2 Social Play Behavior and Cognitive Development .............................................. 197

3.3 Social Play Behavior and Emotional Development .............................................. 198

3.4 Social Play Behavior and Sensorimotor Function............................................... 200

4 The Neural Mechanisms of Social Play Behavior ........................................................ 200

4.1 Frontal Cortical Mechanisms ................................................................................. 201

4.2 Striatal Mechanisms......................................................................................... 203

4.3 Amygdala and Habenula Mechanisms................................................................ 205

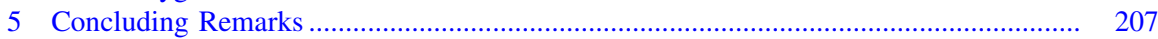

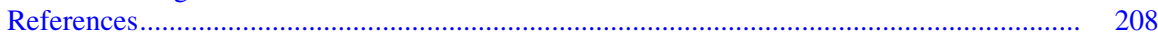

\section{Play Behavior}

Of all the typical events and changes that happen during childhood, one of the most notable is the abundance of play. Play has intrigued biological scientists for many decades (Burghardt 2010; Fagen 1981; Groos 1898; Martin and Caro 1985; Panksepp et al. 1984; Pellis and Pellis 2009; Small 1899; Smith 1982; Špinka et al. 2001; Vanderschuren et al. 1997). It is a form of behavior that is easy to recognize, yet difficult to define. One likely reason for this is that play is probably multifunctional, and as such, it may subserve different functions in different species (Graham and Burghardt 2010; Pellis et al. 2010). Although there is no unitary definition of play, the five categorical criteria outlined by Burghardt (2010), Graham and Burghardt (2010) for recognizing play provide a useful means to describe this behavior. These criteria state that:

1. Play is incompletely functional in the context in which it appears. That is, it includes elements, or is directed toward stimuli that do not contribute to current survival.

2. Play occurs spontaneously and voluntarily. It is pleasurable, rewarding, or performed for its own sake.

3. Play differs from other, more serious behaviors in the form or timing, i.e., it is incomplete, exaggerated, precocious, or involves behavioral patterns with modified form, sequencing, or targeting.

4. Play is performed repeatedly in a similar, but not stereotypic way.

5. Play is initiated in the absence of severe stress, i.e., when the animal is safe, fed, and healthy.

Thus, play is defined by a set of criteria, rather than being a unitary category of behavior. It is not likely that play has a single evolutionary origin or history, and it cannot be considered to have a unitary function (Graham and Burghardt 2010; 
Pellis et al. 2010). It is generally assumed that one of the main functions of play is to facilitate neural and behavioral development in a broad sense. Therefore, it is reasonable to think that the structure of play varies in different species, or sexes, in which different behavioral functions are necessary for survival (think of, e.g., solitary vs. social species, predatory vs. non-predatory species, and different behavioral functions in males vs. females).

By and large, three different subcategories of play can be distinguished: solitary play, object play, and social play. Solitary play, often referred to as locomotor play, refers to apparently spontaneous movements similar to the physical actions of adults, but with no immediate or obvious end goal. Examples of locomotor play include running, leaping, pirouetting, head shaking, heel kicking, and whirling around. Object play can be performed alone or with conspecifics, and it is often prominent in predatory species. Social play involves vigorous interactions between two or more animals. Hence, it is also referred to as rough-and-tumble play (Graham and Burghardt 2010; Pellis and Pellis 2009; Vanderschuren et al. 1997).

Over the last four decades, several functions of play have been postulated. It is beyond the scope of this chapter to summarize these possible functions of play, and the arguments in favor or against these functions. For that purpose, the reader is referred to several excellent texts on this topic (Burghardt 2010; Fagen 1981; Panksepp et al. 1984; Pellis and Pellis 2009; Śpinka et al. 2001; Vanderschuren et al. 1997). With regard to the benefits of play, we will here take the general position that play functions to facilitate the development of social, cognitive, emotional, and motor skills, and the ability to use these capacities flexibly in a changeable and unpredictable environment.

Although there is an abundance of studies on play in a wide variety of species, often performed in naturalistic settings, in this chapter we will focus on studies on social play behavior in the laboratory rat (Rattus Norvegicus). Most laboratory studies on play have investigated social play behavior in rats, since this rodent species (which is among the most widely used species in biomedical research) shows ample social play that is easy to recognize and quantify.

\section{Social Play Behavior in Rats}

The structure of social play behavior in rats has been described in great detail (Baenninger 1967; Bolles and Woods 1964; Panksepp et al. 1984; Panksepp and Beatty 1980; Pellis et al. 1989; Pellis and Pellis 1987, 1998; Poole and Fish 1975; Trezza et al. 2010; Vanderschuren et al. 1997). In rats, social play behavior typically starts with one rat soliciting ('pouncing') another animal, by attempting to nose or rub the nape of its neck (Fig. 1a). The animal that is pounced upon can respond in different ways. If the animal that is pounced upon responds by evading, the soliciting rat may start to chase it, thus making another attempt to launch a play bout. The solicited animal may also rear toward the soliciting animal (also called 'standing defense') and the two animals may rapidly push, paw, and grab each 

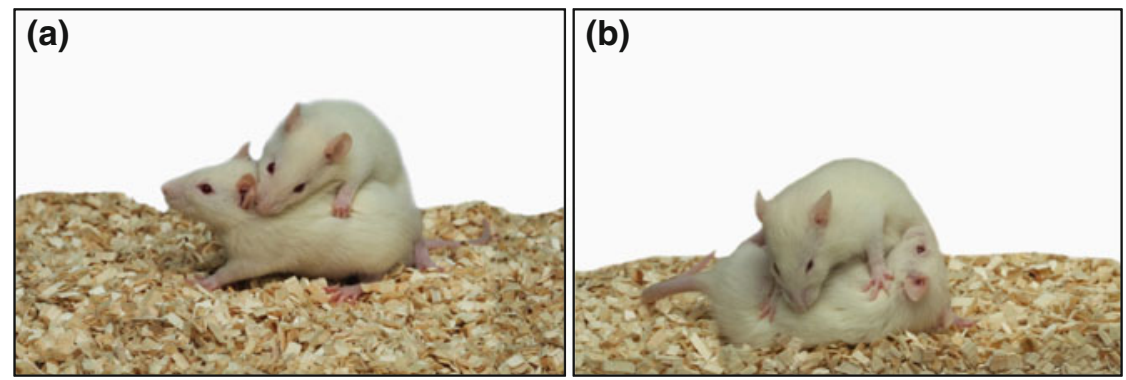

Fig. 1 The most characteristic behaviors during social play in young rats. a Pouncing, i.e., initiation of social play, whereby one rat attempts to nose or rub the nape of the neck of another rat. b Pinning, the most common response to pouncing in juvenile/early adolescent rats. The rat that is pounced upon fully rotates to its dorsal surface, which results in the animal lying with its dorsal surface on the floor with the other animal standing over it. Reproduced from Trezza et al. (2010) Copyright (2010), with permission from Elsevier

other ('boxing'). If the animal that is pounced upon fully rotates to its dorsal surface, 'pinning' is the result, i.e., one animal lying with its dorsal surface on the floor with the other animal standing over it (Fig. 1b). Although pinning most often occurs as a response to pouncing, it can also occur in the absence of an attempt to nape contact (Siviy 2010). From this position, the supine animal can initiate another play bout, by trying to gain access to the other animal's neck. Thus, during social play, pouncing is considered an index of play solicitation, while pinning functions as a releaser of a prolonged play bout (Panksepp and Beatty 1980; Pellis et al. 1989; Pellis and Pellis 1987; Poole and Fish 1975). Pinning and pouncing frequencies can be easily quantified and these are considered the most characteristic parameters of social play behavior in rats (Panksepp and Beatty 1980). During the social encounter, animals may also display social behaviors not directly associated with play, such as sniffing or grooming the partner's body (Panksepp and Beatty 1980; Vanderschuren et al. 1995a).

In rats, social play emerges in the days before weaning (around postnatal days 17-19), and markedly increases in frequency and intensity in the next 2 weeks. It peaks in-between postnatal days 28-40, and declines thereafter as the animals become sexually mature (Baenninger 1967; Bolles and Woods 1964; Meaney and Stewart 1981; Panksepp 1981). It needs to be borne in mind, however, that play does not diminish completely in adulthood. Social play behavior can be observed in adult rats, albeit at low frequencies. Indeed, certain forms of play occur quite abundantly in the adult of many species, including humans, suggesting that play has different functions at different ages (Burghardt 2010; Graham and Burghardt 2010; Pellis and Pellis 2009).

Interestingly, during ontogeny, the structure of social play behavior in rats also changes (Pellis and Pellis 1987; Pellis and Pellis 1990). Whereas pouncing does not change in terms of structure, but rather in frequency, the responses evoked by a pounce do change. Thus, at its onset, standing defense is the most common response, which around weaning (i.e., around postnatal days 21) is replaced by 
rotating to supine as the most likely response. With the onset of puberty, however, rotating to supine declines, so that standing defense becomes the most widely used response. This latter transition, however, occurs only in male rats. During the period when social play is most abundant, therefore, the rotation to supine, resulting in pinning, is the most prominent response to pouncing.

In the remaining parts of this chapter, we will first discuss studies that have investigated the delayed, long-term functions (also referred to as 'distal functions') of social play behavior in rats, using social isolation during the period in life when social play is most abundant. Next, we will discuss the neural substrates of social play behavior in rats, with emphasis on the limbic corticostriatal circuits that underlie emotions and their influence on behavior.

\section{The Developmental Functions of Social Play Behavior}

The importance of social behavior for development has been widely studied using the so-called isolation rearing model. In this paradigm, rats are usually singly housed after weaning for the remainder of the experiment. Isolation rearing has been shown to result in a multitude of neural and behavioral changes (Fone and Porkess 2008; Heidbreder et al. 2000; Robbins et al. 1996), which underscores the importance of social interactions throughout the lifespan for proper behavioral, emotional, and cognitive function. However, since animals are continuously isolated after weaning, it is not clear if the effects induced by isolation rearing are developmentally specific, i.e., if critical periods exist in terms of a long-term influence of social isolation. As such, most isolation rearing studies do not provide explicit information about the importance of social behavior during the period in life when social play typically reaches its highest expression.

There have, however, been several studies from which the importance of social play can be more directly inferred. These have used, for example, a limited period of social isolation, during the period in life when social play is most abundant, followed by resocialization. Thus, animals in such an experiment have experienced social interactions throughout their lives, except for during the period when social play behavior is at its peak. Here, we summarize studies that have used such of comparable approaches, to investigate the importance of social play behavior for social, cognitive, emotional, and sensorimotor development. See Table 1 for an overview of the studies described below.

\subsection{Social Play Behavior and Social Development}

Social isolation of rats during the 4 th and 5 th weeks of life (i.e., postnatal days 22-35) resulted in lower levels of social approach in adulthood (Hol et al. 1999). This apparent reduction in social interest was observed regardless of whether the 
Table 1 Functions of social play behavior inferred from early social isolation studies in rats

Period of social isolat
Social development
Postnatal days 22-35,
$\quad$ followed by
$\quad$ resocialization

Postnatal days 20-50, followed by a month of resocialization

Postnatal days 22-49

Postnatal days 21-42, followed by 2 weeks of resocialization

\section{Cognitive development}

Postnatal days 25-45, followed by resocialization

Postnatal days 21-42, followed by 6 weeks of resocialization

\section{Emotional development}

Postnatal days 21-45, followed by a month of resocialization

Postnatal days 21-51, followed by a month of resocialization

Lower levels of social approach in adulthood; no effects in animals isolated for 1 week only

Reduced social exploration, increased self-grooming and nonsocial exploration during a dyadic encounter; lack of social behaviorinduced conditioned place preference in adulthood

Inability to cope with territorial aggression in adulthood

Increased footshock-induced aggression; Potegal and Einon (1989) no differences in a resident-intruder or muricide paradigm

Increased aggressive behavior, mitigated Meng et al. (2010) by 4 weeks of resocialization

Reduced social interaction with an Lukkes et al. (2009a, b) unfamiliar rat, reversed by treatment with a CRF receptor antagonist into the dorsal raphe nucleus

Slower habituation to novel objects in the Einon and Morgan (1977) open field; this effect was mitigated if Einon et al. (1978) the isolated animals were allowed $1 \mathrm{~h}$ of social interaction per day with a naïve stimulus animal, but not a chlorpromazine or amphetaminetreated stimulus animal; impairment in a response reversal task

Increase in premature responses in the 5- Baarendse et al. (2013a) choice serial reaction time task; no effect in a delay discounting task; retarded acquisition of rat gambling task

Increased latency to leave an opaque

Einon and Morgan (1977) cylinder to explore a novel environment; mitigated by resocialization

Anxiety-like behavior in the elevated plus-maze test
Hol et al. (1999)

Van den Berg et al. (1999a, b, c)

Van den Berg et al. (1999a, b, c); Von

Frijtag et al. (2002)

Einon and Morgan
Einon et al. (1978)

References

Main findings


Table 1 (continued)

\begin{tabular}{|c|c|c|}
\hline Period of social isolation & Main findings & References \\
\hline Postnatal days 20-60 & $\begin{array}{l}\text { Anxiety-like behavior in the elevated } \\
\text { plus-maze test }\end{array}$ & $\begin{array}{l}\text { Lopes da Silva et al. } \\
\qquad(1996)\end{array}$ \\
\hline Postnatal days 30-35 & $\begin{array}{l}\text { Anxiety-like behavior of isolated female } \\
\text { rats in the elevated plus-maze test on } \\
\text { day } 36 \text {; increase in depression-like } \\
\text { behavior in the forced swim and } \\
\text { learned helplessness paradigms on } \\
\text { day } 36\end{array}$ & $\begin{array}{l}\text { Leussis and Andersen } \\
\qquad(2008)\end{array}$ \\
\hline $\begin{array}{l}\text { Postnatal days } 22-35 \text {, } \\
\text { followed by } 6 \text { weeks } \\
\text { of resocialization }\end{array}$ & $\begin{array}{l}\text { No effect in the elevated plus-maze and } \\
\text { shock prod bury tests }\end{array}$ & $\begin{array}{l}\text { Van den Berg et al. } \\
\qquad(1999 a)\end{array}$ \\
\hline $\begin{array}{l}\text { Postnatal days } 22-40 \text {, } \\
\text { followed by } 6 \text { weeks } \\
\text { of resocialization }\end{array}$ & $\begin{array}{l}\text { Reduced levels of burying in the shock } \\
\text { prod bury test }\end{array}$ & Arakawa $(2007 a, b)$ \\
\hline $\begin{array}{l}\text { Postnatal days } 21-42, \\
\text { followed by } 2 \text { weeks } \\
\text { of resocialization }\end{array}$ & $\begin{array}{l}\text { Anxiety-like behavior in a brightly lit } \\
\text { open field; enhanced freezing both } \\
\text { during conditioning and cue-induced } \\
\text { fear expression in the fear } \\
\text { conditioning paradigm }\end{array}$ & Lukkes et al. (2009b) \\
\hline $\begin{array}{l}\text { Postnatal days } 22-35 \text {, } \\
\text { followed by } 5 \text { weeks } \\
\text { of resocialization }\end{array}$ & $\begin{array}{l}\text { Increased sucrose consumption in } \\
\text { adulthood }\end{array}$ & $\begin{array}{l}\text { Van den Berg et al. } \\
\qquad(2000)\end{array}$ \\
\hline Postnatal days 21-42 & $\begin{array}{l}\text { Enhanced amphetamine- and alcohol- } \\
\text { induced conditioned place preference, } \\
\text { slower extinction of amphetamine- } \\
\text { induced conditioned place preference. } \\
\text { No effects in animals isolated at a } \\
\text { later time point (i.e., postnatal days } \\
\text { 42-63) or for a shorter period of time } \\
\text { (i.e., postnatal days } 21-28 \text { ) }\end{array}$ & Whitaker et al. (2013) \\
\hline $\begin{array}{l}\text { Postnatal days } 21-42 \text {, } \\
\text { followed by } 6 \text { weeks } \\
\text { of resocialization }\end{array}$ & $\begin{array}{l}\text { Increased acquisition of cocaine self- } \\
\text { administration and motivation for } \\
\text { cocaine under a progressive ratio } \\
\text { schedule of reinforcement }\end{array}$ & Baarendse et al. (2013b) \\
\hline \multicolumn{3}{|l|}{ Sensorimotor function } \\
\hline $\begin{array}{l}\text { Postnatal days } 21-35 \text {, } \\
\text { followed by } \\
\text { resocialization }\end{array}$ & $\begin{array}{l}\text { Impaired prepulse inhibition of the startle } \\
\text { reflex response; no effect on } \\
\text { locomotor activity }\end{array}$ & Liu et al. (2011) \\
\hline
\end{tabular}

animals were re-housed with animals that had been previously isolated or group housed. However, the decreases in social approach were much less pronounced, or even absent, in animals that had been isolated for 1 week only (either from postnatal days 22-28 or 29-35). In subsequent studies (Van den Berg et al. 1999a, b, c), the social deficit in rats isolated from postnatal days 22-35 was confirmed by showing that these animals showed reduced social exploration, as well as increased self-grooming and nonsocial exploration during a dyadic encounter. Furthermore, unlike control animals, previously isolated rats showed no social 
behavior-induced conditioned place preference in adulthood (Van den Berg et al. 1999b). However, whether this latter result was the consequence of a reduction in the rewarding properties of social behavior, or merely a reduction in social behavior during conditioning, is not clear. Interestingly, sexual behavior was not affected (Van den Berg et al. 1999a). Reduced social interaction with an unfamiliar rat was also reported in another study, in which rats were isolated in between postnatal days 21 and 42, followed by 2 weeks of resocialization (Lukkes et al. 2009b). This effect could be reversed by treatment with a corticotropin releasing factor (CRF) receptor antagonist into the dorsal raphe nucleus (Lukkes et al. 2009a).

The effect of early social isolation on nonaffiliative social behavior in adulthood has also been investigated. In the earliest of these studies (Potegal and Einon 1989), rats were socially isolated from postnatal days 20-50, and resocialized for a month thereafter. Interestingly, this study also included a group of rats that was isolated, but allowed $1 \mathrm{~h}$ of social interaction every day (which for the most part consisted of social play), a procedure that had previously been shown to mitigate the long-lasting effects of social isolation (Einon et al. 1978; Einon and Morgan 1977). When tested as adults, there were no differences between the groups in a resident-intruder or muricide paradigm. However, footshock-induced aggression was increased in the isolated animals, whereas the control and the animals allowed 1-h social interaction did not differ. Two later studies also investigated the effect of early social isolation on aggressive behavior (Van den Berg et al. 1999a; Von Frijtag et al. 2002). It appeared from these studies that social isolation during postnatal days 22-35 severely compromised the ability to cope with territorial aggression in adulthood. The isolated rats took more time to assume a submissive posture during an encounter with a dominant, territorial rat. When the resident was subsequently confined in a small cage in its territory, control animals showed marked immobility, whereas the isolates did not. Moreover, plasma concentrations of corticosterone and adrenaline were profoundly elevated in the isolates (Van den Berg et al. 1999a). In a follow-up study, an aggressive rat was introduced into groups of isolated or control rats. In this setting, the isolated rats were bitten more often, evoked more piloerection in the aggressor, and vocalized more often. In addition, in the absence of the aggressor, the isolates showed less putative de-arousal behaviors, such as grooming and play (Von Frijtag et al. 2002). Recently, Meng et al. (2010) demonstrated that rats socially isolated from postnatal days 21-49 showed increased aggressive behavior and social interaction than socially reared controls. However, both effects were mitigated by 4 weeks of resocialization (Meng et al. 2010).

Altogether, the studies described above demonstrate that social isolation during the period in life when social play behavior peaks induces long-lasting social impairments that range from subtle changes in affiliative behavior to a profound impairment in dealing with a challenging social situation. 


\subsection{Social Play Behavior and Cognitive Development}

The earliest studies that have investigated the effect of social isolation during development on measures of cognition (Einon et al. 1978; Einon and Morgan 1977) compared different social isolation regimes, and their effects on behavior. Of particular relevance here is the observation that social isolation in-between postnatal days 25-45, followed by resocialization, caused a lasting effect on exploration of novel objects in an open field. That is, whereas control animals quickly habituated to the presence of the objects (i.e., they investigated the objects, but this quickly declined over a 30-min test), the isolated were much slower to habituate (Einon and Morgan 1977). Interestingly, social isolation before postnatal day 25 or after day 45 did not evoke this change in behavior. A subsequent study showed that the effect of social isolation on object exploration was mitigated if the isolated animals were allowed $1 \mathrm{~h}$ of social interaction per day. This beneficial effect of social interaction was much reduced, however, if the stimulus animals during the $1 \mathrm{~h}$ social interactions were treated with chlorpromazine or amphetamine (Einon et al. 1978). Interestingly, these are drugs that are well known to suppress social play behavior (Trezza et al. 2010; Vanderschuren et al. 1997), suggesting that the beneficial effects of social interaction are the result of playful social behavior. These authors also showed that social isolation induced an impairment in a response reversal task, in which rats had to switch strategies to remove a ball from a tube to gain access to a food reward (Einon et al. 1978). That is, isolates were slower to reverse their strategy than controls or isolates that were allowed $1 \mathrm{~h}$ of social interaction.

Recently, the effects of early social isolation in more complex cognitive tasks have been investigated (Baarendse et al. 2013a). This study investigated the longlasting effects of social isolation between postnatal days 21 and 42 on tasks of attention, impulsivity, and decision making. Performance in a delay discounting task, where animals have to choose between a small, immediately delivered, and a larger, delayed food reward was not affected by social isolation. This indicates that the choice dimension of impulsive behavior was not altered after social isolation. However, behavioral impairments did emerge in the 5-choice serial reaction time task, in which rats have to make a nose-poke response into one of five apertures that are illuminated in a pseudorandom fashion. Under baseline conditions, the isolates performed as well as controls, but when task contingencies were unexpectedly altered, by increasing the intertrial interval or reducing the duration of the instructive light signal, isolates displayed an increase in premature responses, which is indicative of increased impulsive action. Interestingly, measures of attention were not affected in the task. Moreover, whereas control animals showed an increase in premature responses after drug challenges that increase dopaminergic neurotransmission (i.e., amphetamine, or the dopamine reuptake blocker GBR12909), this effect was blunted in the isolated rats. Another cohort of animals was tested in a rat version of the Iowa gambling task. In this task, rats have to learn to develop a preference for response options that yield small rewards with a high 
probability, in favor of options that deliver larger rewards, but with a lower probability, and longer time-out punishments in case of nonreinforcement (Zeeb et al. 2009). In this experiment, control animals showed a clear learning curve in the first session of the task, quickly developing a preference for the advantageous response options, whereas the previously isolated rats showed no learning curve whatsoever. With further training, however, the isolated animals did acquire the task to the same level as controls (Baarendse et al. 2013a).

In sum, social isolation during a play-enriched period in life causes long-lasting cognitive deficits. Interestingly, these impairments are most apparent in novel or challenging situations.

\subsection{Social Play Behavior and Emotional Development}

Studies on the role of social play behavior in the development of emotional capacities have mainly focused on two aspects of emotion, i.e., anxiety and reward. In the context of anxiety, Einon and Morgan (1977) were the first to report on the effects of early social isolation. They found that social isolation from postnatal day 25 until 45 increased the latency of animals to leave an opaque cylinder to explore a novel environment. However, this increase in anxiety-like behavior was merely the result of present social isolation, since the effect disappeared with resocialization, and was also found in animals socially isolated at later ages.

In the elevated plus maze, increased anxiety has also been observed after early social isolation, although this may depend on the exact timing and/or duration of social isolation. Thus, isolation from postnatal day 21 until 51, followed by 30 days of social housing led to increased anxiety. However, social isolation at a later age (postnatal days 51-81) did not alter behavior on the elevated plus maze (Wright et al. 1991). A comparable increase in anxiety was found after isolation from postnatal days 30-60, although in that study, the animals were tested when still isolated (Lopes da Silva et al. 1996). Social isolation from postnatal days 30-35 increased anxiety on the elevated plus maze on day 36, but in female rats only (Leussis and Andersen 2008). In contrast, social isolation from postnatal days 22-35, followed by resocialization for 6 weeks, did not alter behavior on the elevated plus maze (Van den Berg et al. 1999a).

The latter study also investigated the effect of early social isolation in the shock prod bury test. These animals were socially isolated from postnatal days 22-35, followed by 6 weeks of social housing, and unlike the dramatic effects in the resident-intruder test (see above), behavior in the shock prod bury test was not altered (Van den Berg et al. 1999a). This finding contrasts with the reports that early social isolation does change later behavior in this test (Arakawa 2007a, b). In these studies, social isolation from postnatal days 26-40, followed by 6 weeks of resocialization caused the animals to show reduced levels of burying. Interestingly, this effect was also observed in female, but not male rats that were isolated as adults (Arakawa 2007b). Moreover, the effect of early social isolation 
on burying was mitigated by housing the animals after isolation with a previously nonisolated conspecific. Again, this effect was only observed in female rats (Arakawa 2007a).

Lukkes et al. (Lukkes et al. 2009b) studied behavior in different paradigms of fear and anxiety after early social isolation. In these experiments, the rats were socially isolated from postnatal days $21-42$ followed by 2 weeks of resocialization. The isolated rats showed a modest increase in anxiety-like behavior (i.e., reduced entries into the center) in a brightly lit open field. In addition, social interaction was somewhat reduced (see above), which was accompanied by a marked increase in freezing during the social interaction test. In a fear conditioning test, the isolates showed enhanced freezing, both during conditioning and during cue-induced fear expression. Plasma corticosterone levels during restraint stress did not differ between isolates and controls, however. In follow-up studies, these authors identified interactions between CRF and serotonin as a possible underlying mechanism of the social isolation-induced increases in anxiety (Lukkes et al. 2009a, c).

The effect of early social isolation on depression-like behavior was assessed in one study (Leussis and Andersen 2008). These authors showed that social isolation from postnatal days 30-35 led to an increase in depression-like behavior in the forced swim and learned helplessness paradigms, although these effects were somewhat different between males and females. It needs to be borne in mind that behavior was analyzed immediately after social isolation (i.e., on postnatal day 36), which leaves the possibility open that the behavioral changes were an acute effect of social isolation.

In the context of reward-related behavior, it was found that social isolation from postnatal days 22-35, followed by 5 weeks of resocialization, caused an increase in sucrose consumption in adulthood (Van den Berg et al. 2000). Interestingly, allowing the animals 30 min of social interaction during the period of social isolation seemed to reduce, but not completely block, the effect of isolation. Remarkably, conditioned hyperactivity before sucrose presentation was reduced after early social isolation (Van den Berg et al. 1999b). The effect of early social isolation on the rewarding effects of drugs of abuse have been investigated in two studies so far. In the first of these, rats that had been socially isolated from postnatal days 21-42 showed enhanced amphetamine- and alcohol-induced conditioned place preference (Whitaker et al. 2013). In addition, socially isolated rats displayed slower extinction of amphetamine-induced conditioned place preference. These effects were not observed in animals that had been socially isolated at a later time point (i.e., postnatal days 42-63) or for a shorter period of time (i.e., postnatal days 21-28). Neurobiologically, the socially isolated rats showed increased excitatory drive onto dopaminergic neurons in the ventral tegmental area (Whitaker et al. 2013). In another study on the effect of early social isolation on drug reward, it was shown that social isolation from postnatal days 21-42 followed by 6 weeks of resocialization increased the acquisition of cocaine self-administration. Moreover, the isolated rats showed marked increases in the motivation for cocaine under a progressive ratio schedule of reinforcement. The reinforcing properties of cocaine 
(assessed using a dose-response analysis of self-administration), or extinction and reinstatement of responding were not altered (Baarendse et al. 2013b).

In sum, there is evidence to indicate that early social isolation causes a longlasting increase in anxiety-like behavior. These changes, however, appear to depend upon the length or interval of isolation, and on the sex of the animal. In addition, early social isolation increases the rewarding and motivational properties of drugs of abuse, and alters the rewarding effects of sucrose.

\subsection{Social Play Behavior and Sensorimotor Function}

It has repeatedly been shown that rats reared in isolation show locomotor hyperactivity and impaired prepulse inhibition of an acoustic startle reflex at adulthood (for reviews see Geyer et al. 1993, 2001; Hall 1998; Li et al. 2009). Prepulse inhibition (PPI) of the startle reflex response refers to the ability of a weak prestimulus (prepulse) to transiently inhibit the response to a closely following strong sensory stimulus (pulse). PPI is detected in numerous species ranging from rodents to humans. Deficits in PPI are believed to be linked to dysfunction in the sensorimotor gating function (Koch 1999; Fendt et al. 2001) and are observed in patients with schizophrenia, schizotypal personality disorder, obsessivecompulsive disorder, and Huntington's disease. Liu and colleagues investigated if critical developmental periods exist during which isolation rearing negatively affects locomotor activity and the PPI response (Liu et al. 2011). Locomotor activity and PPI were measured in three groups of adult rats: socially housed controls, rats reared in isolation throughout life, and rats reared in isolation for the first 2 weeks after weaning followed by social housing. The results of this study revealed that locomotor activity increased only in rats reared in isolation throughout life but not in the other two groups. Conversely, the impairment of PPI was seen both in rats reared in isolation for the first 2 weeks and in rats reared in isolation throughout life, meaning that the hyperactivity but not the deficits of PPI induced by isolation rearing could be ameliorated by resocialization (Liu et al. 2011). This suggests that critical periods exist in the effects of isolation rearing on sensorimotor gating function but not locomotor activity. It is therefore tempting to speculate that the gating ability depends considerably on the neuronal activities involved in social play.

\section{The Neural Mechanisms of Social Play Behavior}

The studies summarized above suggest that social play behavior serves to facilitate the development of social, cognitive, and emotional capacities, and their neural substrates. Clearly, social play behavior itself also depends upon coordinated activity in the neural circuits underlying social, cognitive, and emotional processes, 
as the animal needs to perceive the presence of a potential playmate, to understand the conspecific's actions and intentions and to respond appropriately. Moreover, given that social play behavior is a highly rewarding activity, neural mechanisms underlying positive emotions are also engaged during play. Indeed, studies in the last three decades have yielded an emerging body of evidence to outline the neural mechanisms of social play behavior in rats. These studies have employed lesion, immediate early gene expression, and intracranial drug infusion approaches. Below, we will provide a summary of these studies.

\subsection{Frontal Cortical Mechanisms}

Immediate early gene studies have shown increased cellular activity in frontal cortical areas implicated in higher cognitive, so-called executive functions, during social play behavior. Thus, one early study found no changes in expression of the immediate early gene c-fos in the orbitofrontal and anterior cingulate cortex (Gordon et al. 2002), although social play did increase levels of brain-derived neurotrophic factor in the dorsolateral frontal cortex (Gordon et al. 2003). However, detailed analysis of c-fos expression in a wide range of cortical areas in a more recent study did reveal increases in activity in several frontal regions, including the anterior cingulate, prelimbic, medial orbital, and ventrolateral orbital cortex, as well as a decrease in activity in the dorsolateral orbital cortex (Van Kerkhof et al. 2013c). Moreover, analysis of activity in prefrontal afferents and efferents revealed that c-fos expression after social play correlated between the prelimbic, infralimbic, and agranular insular cortex and their striatal efferents. In addition, correlated activity between anterior cingulate, prelimbic, infralimbic, and several orbital cortical subregions and the basolateral amygdala was found (Van Kerkhof et al. 2013c). Thus, social play behavior appears to be associated with coordinated cellular activity in a distributed limbic corticostriatal network (see Fig. 2).

Several studies have investigated the role of the prefrontal cortex in the development of social play. In these studies, frontal areas were lesioned in neonatal rats (typically in between postnatal days 3 and 7). Neonatal ablation of the frontal cortex was shown to result in increases in pouncing, yet shorter durations of pinning (Panksepp et al. 1994). Another study showed that neonatal excitotoxic lesions of the medial prefrontal cortex caused the structure of social play to be altered, as lesioned rats used more partial rotation and less complete rotation (with equal rates of play solicitation), resulting in a reduction in pinning (Schneider and Koch 2005). These findings are more or less consistent with those in a later study that found that neonatal ablation of the medial prefrontal cortex induces rats to initiate more play, but respond less and differently to play initiation (i.e., more evasions and less complete rotations) (Bell et al. 2009). Interestingly, neonatal lesions of the orbitofrontal cortex resulted in a different pattern of effects. Thus, these lesions resulted in rats no longer adapting their social play behavior to the 


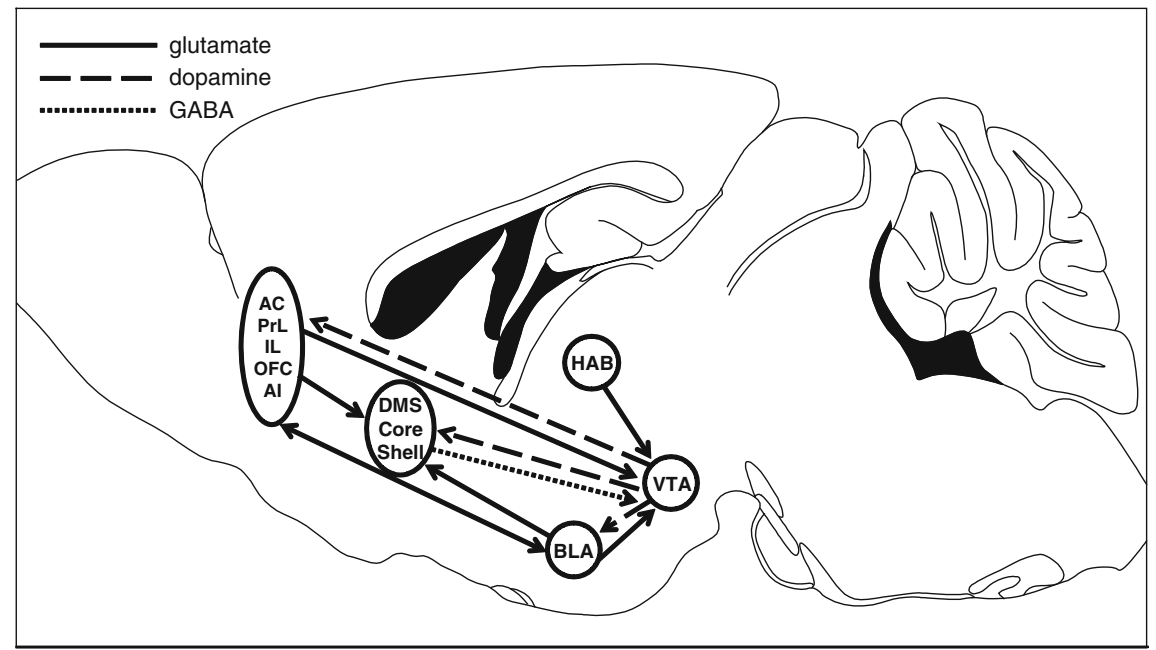

Fig. 2 Simplified scheme of the neural pathways implicated in social play behavior in rats described in this chapter. Abbreviations: $A C$ anterior cingulate cortex, $\operatorname{Pr} L$ prelimbic cortex, $I L$ infralimbic cortex, $O F C$ orbitofrontal cortex, $A I$ agranular insular cortex, $D M S$ dorsomedial striatum, Core nucleus accumbens core, Shell nucleus accumbens shell, BLA basolateral amygdala, $H A B$ habenula, VTA ventral tegmental area. Solid lines glutamatergic projections, dashed lines dopaminergic projections, stippled line GABAergic projection. The five frontal regions (AC, PrL, IL, OFC, AI) send topographically organized projections to the striatum. The AC and OFC project predominantly to the DMS, the PRL projects to the DMS and core, and the $\mathrm{IL}$ and AI predominantly project to the shell. Not in this scheme is a prominent indirect projection from the habenula to the VTA, via the rostromedial tegmental nucleus, which sends a GABAergic projection to the VTA

dominance status of the conspecific partner (Pellis et al. 2006). Together, these studies indicate that prefrontal cortical regions may not be critical for the development of social play behavior per se, but rather to develop the capacities to finetune ongoing social play to fit the demands of the social and physical environment.

One needs to bear in mind though that the studies described above used neonatal lesions. As such, they are probably more informative about the role of these brain structures in the development of social play, than of their role in the expression of social play in an otherwise normal animal. Moreover, functional compensation by non-lesioned regions, which is particularly pertinent in developing animals, may lead to an underestimation of the lesion effect. For that reason, a recent study has investigated the role of medial prefrontal regions in the expression of social play behavior using pharmacological inactivation methods. Thus, infusion of a mixture of the GABA-A receptor agonist muscimol and the GABA-B receptor agonist baclofen into either the prelimbic, the infralimbic, or the medial/ventral orbital frontal cortex markedly reduced the frequency and duration of social play behavior (Van Kerkhof et al. 2013b). Given the role of these regions in higher cognitive functions such as attention, planning, working 
memory, and impulse control, it is likely that they subserve related functions in the context of social interactions as well, aiding in the flexible adaptation of behavior in a changeable, unpredictable environment. A different approach was taken by Siviy and colleagues (Siviy et al. 2011). They took advantage of the fact that Fischer 344 rats display profoundly reduced levels of social play than other rat strains commonly used in biomedical research. Compared to Sprague-Dawley rats, it appeared that the reduced levels of social play were associated with increased dopamine levels, but reduced dopamine turnover in the prefrontal cortex. Moreover, Fischer 344 rats showed impairments in corticostriatal neuroplasticity.

The studies summarized above demonstrate the importance of the prefrontal cortex for social play behavior. Conversely, the role of social play for the development of the prefrontal cortex has been assessed in several studies that used social isolation or modified social housing conditions. Thus, social isolation from postnatal days 30-35 caused a reduction in prefrontal levels of the plasticityassociated proteins myelin basic protein, synaptophysin, and spinophillin (Leussis and Andersen 2008) on day 36. Prefrontal synaptophysin levels remained reduced when assessed after several weeks of resocialization, on postnatal day 60 (Leussis et al. 2008). In addition, social isolation from postnatal days 18-32 followed by 1 month of resocialization increased the number of neurons immunoreactive for vasoactive intestinal peptide, and reduced dendritic arborization in the medial prefrontal cortex (Pascual et al. 1996). Consistently housing rats from postnatal days 21-60 with non-playful adult females reduced dendritic arborization in the medial prefrontal (but not the orbital frontal) cortex (Bell et al. 2010). Electrophysiological analysis in a recent study showed that the reduction in the amplitude of excitatory postsynaptic potentials in the medial prefrontal cortex by dopamine receptor stimulation was blunted after social isolation from postnatal days 21-42 followed by 6 weeks of resocialization (Baarendse et al. 2013a). Last, analysis of opioid receptor binding showed that social isolation from postnatal days 22-35 followed by 5 weeks of resocialization reduced kappa-, but not mu-opioid receptor density in the prefrontal cortex (Van den Berg et al. 1999c). Together, these studies emphasize the importance of juvenile (and playful) social interaction for the maturation of the morphology and plasticity of neurons in the medial prefrontal cortex.

\subsection{Striatal Mechanisms}

The two available immediate early gene expression studies carried out in rats are consistent in showing increased c-fos expression in both dorsal striatum and nucleus accumbens (core and shell subregions) after social play (Gordon et al. 2002; Van Kerkhof et al. 2013c). Interestingly, striatal c-fos expression levels correlated with those in their inputs from prelimbic, infralimbic, agranular insular 
cortex, as well from basolateral amygdala, reinforcing the notion (see above) that expression of social play behavior is subserved by a distributed limbic corticostriatal network (Van Kerkhof et al. 2013c) (see Fig. 2).

Functional studies have also revealed contributions of striatal mechanisms to social play behavior. Pharmacological inactivation of striatal subregions, using a mixture of muscimol and baclofen, or using the AMPA glutamate receptor antagonist DNQX, confirmed involvement of striatal mechanisms to social play. Thus, DNQX infusion in the dorsomedial striatum increased social play, whereas muscimol/baclofen administration into the nucleus accumbens core increased the duration of social play (Van Kerkhof et al. 2013b). Thus, functional activity within the striatum appears to exert inhibitory influence over the expression of social play, consistent with the notion that reward-related behavior is associated with reduced neuronal activity in the nucleus accumbens (Carlezon and Thomas 2009; Taha and Fields 2006), and that the dorsomedial striatum is involved in certain forms of response inhibition (Eagle and Baunez 2010). Neonatal intraventricular administration of 6-hydroxydopamine, causing profound depletion of striatal dopamine (and to a lesser extent, noradrenaline, while increasing striatal serotonin), led to a structural difference in social play. Lesioned animals used a behavioral strategy that resulted in shortened play bouts, suggesting that striatal mechanisms are involved in the sequential organization of social play (Pellis et al. 1993). The involvement of striatal dopamine was also assessed using fast-scan cyclic voltammetry, in a study that showed that social interaction in 4-week old rats induced increased dopamine activity in the nucleus accumbens core (although this study did not explicitly assess whether the social interaction was playful or not) (Robinson et al. 2011). Consistent with a role for striatal dopamine in social play, non-playful Fischer 344 rats showed increased levels of dopamine, but reduced dopamine turnover in the striatum (Siviy et al. 2011). Other studies investigated the role of striatal opioids in social play. Using an ex vivo autoradiography approach, social play was found to be associated with increased opioid activity in the anterior nucleus accumbens (Vanderschuren et al. 1995b). Consistent with a role for nucleus accumbens opioids in social play, Trezza et al. (Trezza et al. 2011) found that infusion into the nucleus accumbens of morphine, beta-endorphin, as well as the mu-opioid receptor agonist DAMGO increased, where intra-accumbens infusion of the mu-opioid receptor antagonist CTAP reduced social play. Interestingly, the play-enhancing effect of systemic morphine administration was prevented by intra-accumbens treatment with the opioid receptor antagonist naloxone, indicating that stimulation of opioid receptors (most likely of the mu-type, since stimulation of delta-opioid receptors did not affect social play, and infusion of a kappa-opioid receptor agonist even reduced social play) is necessary and sufficient to enhance social play behavior in rats. Moreover, intra-accumbens treatment with CTAP prevented the development of social play-induced conditioned place preference, indicating that nucleus accumbens mu-opioid receptors mediate the rewarding properties of social play. Recently, the role of endocannabinoids within the nucleus accumbens in social play behavior was also investigated (Trezza et al. 2012). Social play was shown to increase 
concentrations of the endocannabinoid anandamide within the nucleus accumbens, and intra-accumbens infusion of URB597, which inhibits the enzymatic breakdown of anandamide, increased social play. However, the play-enhancing effect of systemic treatment with URB597 (Trezza and Vanderschuren 2008a, b) was not affected by intra-accumbens treatment with the CB1 cannabinoid receptor antagonist rimonabant, suggesting that the primary site of action of systemic URB597 to increase play is not within the nucleus accumbens (Trezza et al. 2012).

There is only limited information on the effects of early social isolation on striatal function. Thus, in contrast to the changes observed within the prefrontal cortex (see above), social isolation from postnatal days 30-35, followed by 5 weeks of social housing, did not alter synaptophysin expression in any subregion of the (dorsal or ventral) striatum (Leussis et al. 2008). In their social isolation study, Van den Berg and colleagues (Van den Berg et al. 1999c) found no changes in the density of mu-, delta-, or kappa-opioid receptors in the ventral or dorsal striatum.

In sum, dopaminergic, opioid, and cannabinoid neurotransmission within the nucleus accumbens plays an important role in the expression of social play behavior. Furthermore, functional activity in several striatal subregions controls the expression of social play. However, whether early social isolation has longlasting consequences for striatal function remains to be elucidated.

\subsection{Amygdala and Habenula Mechanisms}

When cellular activity was assessed, Gordon et al. (Gordon et al. 2002; Gordon et al. 2003) found that social play induced increased expression of brain-derived neurotrophic factor, but not the immediate early gene c-fos, in the amygdala. One explanation for this latter finding may be that activity within the entire amygdala was assessed. Thus, a recent study, which analyzed c-fos activity within four subregions of the amygdala after social play (Van Kerkhof et al. 2013c) found that c-fos expression was increased in the lateral, but not basolateral, central, or medial amygdala after social play. Interestingly, even though cellular activity within the basolateral amygdala was not significantly increased after social play, it correlated with activity in its prefrontal (anterior cingulate, prelimbic, intralimbic, orbital, agranular insular cortex) and striatal (nucleus accumbens core and shell, olfactory tubercle) afferents and efferents. Activity within the medial amygdala was also found to be correlated to activity within the medial prefrontal, orbital, and agranular insular cortex. In a related study, it was shown that short-term social isolation (up to $24 \mathrm{~h}$ ) increased c-fos expression within the habenula, and that a subsequent episode of social play reduced this activity within the medial sector of the lateral habenula, suggesting that the habenula mediates the negative emotional aspects of social isolation, which is mitigated by the opportunity for subsequent social play (Van Kerkhof et al. 2013a). 
Lesion studies support the involvement of the amygdala in social play. Thus, both neonatal (postnatal day 7) and juvenile (postnatal day 21) electrolytic or excitotoxic lesions of the amygdala reduced social play behavior (Daenen et al. 2002; Meaney et al. 1981). Interestingly, in one of these studies (Meaney et al. 1981), amygdala lesions only affected social play behavior in male rats, whereas in the other (Daenen et al. 2002) only male rats were used, which leaves the question open as to whether these lesion effects are sex-dependent. These observations resonate well with a more recent study that found, that neonatal (postnatal days 0-2) suppression of the expression of the gene expression regulator methyl-CpG-binding protein 2 within the amygdala reduced social play behavior during postnatal days $25-29$, but only in male rats (Kurian et al. 2008).

Functional studies also support the involvement of these limbic structures in social play. Thus, as in the nucleus accumbens, levels of the endocannabinoid anandamide were elevated in the amygdala after social play, as was the phosphorylation of CB1 cannabinoid receptors, which is thought to be a consequence of receptor activation. Furthermore, infusion of URB597 into the basolateral amygdala increased social play, whereas the stimulating effect on social play induced by systemic treatment with URB597 was blocked by infusion of the cannabinoid receptor antagonist rimonabant into the basolateral amygdala (Trezza et al. 2012). These data identify the basolateral amygdala as an important site of action of endocannabinoids to modulate social play behavior. Involvement of the habenula was investigated using pharmacological inactivation with muscimol/ baclofen (Van Kerkhof et al. 2013a), which resulted in a reduction in social play behavior. Interestingly, habenula inactivation had a less pronounced effect on play solicitation (i.e., pouncing) than on the response to solicitation (i.e., pinning), suggesting that the habenula is particularly involved in the responsiveness to play solicitation.

As for the effects of early social isolation on amygdala function, Leussis et al. (Leussis and Andersen 2008) found that social isolation from postnatal days 30-35 reduced the expression of spinophillin in the basolateral and central amygdala on day 36. Whereas levels of synaptophysin and myelin basic protein were not altered, they also found that social isolation increased expression of tyrosine hydroxylase in the basolateral amygdala in male rats, but decreased it in female rats. Analysis of opioid receptor density showed that mu- (but not delta- or kappa-) opioid receptor binding was increased in the basolateral amygdala after social isolation from postnatal days 22-35 followed by 5 weeks of social housing (Van den Berg et al. 1999c).

Together, these studies emphasize the role of limbic regions, such as the amygdala and habenula, in social play behavior. In particular, the amygdala appears to be involved in sex differences in social play, as well as in mediating the stimulatory effects of endocannabinoids on social play. Moreover, social play seems to subserve proper development of the amygdala. The habenula, in turn, is involved in both positive (i.e., mediating social play itself) and negative (i.e., the negative emotions associated with social isolation) social phenomena in young rats. 


\section{Concluding Remarks}

The studies described above demonstrate the importance of social play behavior for social, cognitive, emotional, and sensorimotor development. Thus, social isolation during a restricted period in life when social play behavior is highly abundant causes an array of deficits in these domains. Remarkably, both the social and cognitive deficits emerge in particular when animals are challenged, such as when in a strenuous social situation, or when confronted with sudden changes in task requirements. Moreover, early social isolation causes increase in anxiety-like behavior, and enhances the sensitivity to drugs of abuse. As for the neural substrates affected, the majority of studies so far have focused on prefrontal cortical mechanisms. Thus, post-weaning social interaction likely facilitates maturation of the prefrontal cortex, while there is only scant data for other neural structures affected by social isolation.

Studies on the neural mechanisms of social play have revealed a network of interconnected limbic corticostriatal regions underlying this behavior (Fig. 2). c-Fos expression was found to be correlated in prefrontal cortical, orbital cortical, striatal, and amygdaloid regions after social play. Of these, the prefrontal cortex seems to be involved in some of the higher cognitive aspects of social play, such as adapting the social behaviors of an animal to the changing circumstances in its social and physical environment. Moreover, opioid neurotransmission within the nucleus accumbens, perhaps in concert with amygdala endocannabinoid activity, mediates the positive emotional properties of social play behavior, whereas functional activity in dorsomedial striatum and nucleus accumbens core may serve to control the expression of social play in an appropriate setting. One remarkable finding that seems to emerge from these analyses is that amygdala involvement in social play seems more pertinent for male than for female rats. In addition, recent studies have also revealed a role for the habenula in social play.

Thus, there is an emerging, and quite consistent body of evidence to indicate that social play is mediated by coordinated activity in a limbic corticostriatal network, and that it, in turn, may serve to stimulate the functional development of these circuits. Several questions remain, however. Most important perhaps is the need for further study of the brain regions and signaling mechanisms involved. Given the importance of social play for behavioral development, it is remarkable that it has received relatively little research attention in the neuroscience field. For example, not many studies have tried to separately study rewarding, motivational, and cognitive aspects of social play (Achterberg et al. 2012; Peartree et al. 2012; Thiel et al. 2008, 2009; Trezza et al. 2009), but it is highly likely that these are mediated by dissociable neural mechanisms. In addition, studies that have investigated the role of social play in behavioral development, have for the most part used social isolation approaches. Notwithstanding the important information this research has yielded, these experiments leave the question open of whether it is the lack of social play that causes the neural and behavioral changes, or that other factors, such as lack of non-playful social activities, or stress as a result of social 
isolation are involved as well. This issue can be addressed using somewhat more sophisticated approaches, such as allowing the animals a limited amount of (playful) social interaction every day (e.g., Einon et al. 1978), or housing them with non-playful, adult females (e.g., Bell et al. 2010). Other issues to be addressed in future studies include elucidation of the sensitive periods within which social play is essential for development, since the social isolation studies summarized here used a wide range of social isolation periods, as well as different periods of resocialization afterwards. With regard to resocialization, one important topic is whether the effects of deprivation of social play can be mitigated by housing the isolates together with previously nonisolated animals, i.e., rats that had normal social play experience as juveniles and early adolescents.

In conclusion, studies in the last four decades have indicated that the importance of social play behavior for proper maturation of brain and behavior should not be underestimated. It is a wonderful challenge for future research to deepen our knowledge on the brain mechanisms of social play, and the mechanisms by which this intriguing activity contributes to welfare and development.

Acknowledgments Supported by National Institute on Drug Abuse Grant R01 DA022628 (L.J.M.J.V.), Netherlands Organization for Scientific Research (NWO) Veni grant 91611052 (V.T.) and Marie Curie Career Reintegration Grant PCIG09-GA-2011-293589 (V.T.).

\section{References}

Achterberg EJM, Trezza V, Vanderschuren LJMJ (2012) Beta-adrenoreceptor stimulation mediates reconsolidation of social reward-related memories. PLoS One 7:e39639

Arakawa H (2007a) Ontogenetic interaction between social relationships and defensive burying behavior in the rat. Physiol Behav 90:751-759

Arakawa H (2007b) Ontogeny of sex differences in defensive burying behavior in rats: effect of social isolation. Aggr Behav 33:38-47

Baarendse PJJ, Counotte DS, O'Donnell P, Vanderschuren LJMJ (2013a) Early social experience is critical for the development of cognitive control and dopamine modulation of prefrontal cortex function. Neuropsychopharmacology 38:1485-1494

Baarendse PJJ, Limpens JHW, Vanderschuren LJMJ (2013b) Disrupted social development enhances the motivation for cocaine. Psychopharmacology doi:10.1007/s00213-013-3362-8

Baenninger LP (1967) Comparison of behavioural development in socially isolated and grouped rats. Anim Behav 15:312-323

Bell HC, McCaffrey DR, Forgie ML, Kolb B, Pellis SM (2009) The role of the medial prefrontal cortex in the play fighting of rats. Behav Neurosci 123:1158-1168

Bell HC, Pellis SM, Kolb B (2010) Juvenile peer play experience and the development of the orbitofrontal and medial prefrontal cortices. Behav Brain Res 207:7-13

Bolles RC, Woods PJ (1964) The ontogeny of behavior in the albino rat. Anim Behav 12:427-441

Burghardt GM (2010) The comparative reach of play and brain: perspective, evidence, and implications. Am J Play 2:338-356

Carlezon WA Jr, Thomas MJ (2009) Biological substrates of reward and aversion: a nucleus accumbens activity hypothesis. Neuropharmacology 56(Suppl. 1):122-132 
Daenen EWPM, Wolterink G, Gerrits MAFM, Van Ree JM (2002) The effects of neonatal lesions in the amygdala or ventral hippocampus on social behaviour later in life. Behav Brain Res 136:571-582

Eagle DM, Baunez C (2010) Is there an inhibitory-response-control system in the rat? Evidence from anatomical and pharmacological studies of behavioral inhibition. Neurosci Biobehav Rev 34:50-72

Einon DF, Morgan MJ (1977) A critical period for social isolation in the rat. Dev Psychobiol 10:123-132

Einon DF, Morgan MJ, Kibbler CC (1978) Brief periods of socialization and later behavior in the rat. Dev Psychobiol 11:213-225

Fagen R (1981) Animal play behavior. Oxford University Press, Oxford

Fendt M, Li L, Yeomans JS (2001) Brain stem circuits mediating prepulse inhibition of the startle reflex. Psychopharmacology 156:216-224

Fone KCF, Porkess MV (2008) Behavioural and neurochemical effects of post-weaning social isolation in rodents- relevance to developmental neuropsychiatric disorders. Neurosci Biobehav Rev 32:1087-1102

Geyer MA, Wilkinson LS, Humby T, Robbins TW (1993) Isolation rearing of rats produces a deficit in prepulse inhibition of acoustic startle similar to that in schizophrenia. Biol Psychiatry 134:361-372

Geyer MA, Krebs-Thomson K, Braff DL, Swerdlow NR (2001) Pharmacological studies of prepulse inhibition models of sensorimotor gating deficits in schizophrenia: a decade in review. Psychopharmacology 156:117-154

Gordon NS, Kollack-Walker S, Akil H, Panksepp J (2002) Expression of c-fos gene activation during rough and tumble play in juvenile rats. Brain Res Bull 57:651-659

Gordon NS, Burke S, Akil H, Watson SJ, Panksepp J (2003) Socially-induced brain 'fertilization': play promotes brain derived neurotrophic factor transcription in the amygdala and dorsolateral frontal cortex in juvenile rats. Neurosci Lett 341:17-20

Graham KL, Burghardt GM (2010) Current perspectives on the biological study of play: signs of progress. Q Rev Biol 85:393-418

Groos K (1898) The play of animals. D Appleton, New York

Hall FS (1998) Social deprivation of neonatal, adolescent, and adult rats has distinct neurochemical and behavioral consequences. Crit Rev Neurobiol 12:129-162

Heidbreder CA, Weiss IC, Domeney AM, Pryce C, Homberg J, Hedou G, Feldon J, Moran MC, Nelson P (2000) Behavioral, neurochemical and endocrinological characterization of the early social isolation syndrome. Neuroscience 100:749-768

Hol T, Van den Berg CL, Van Ree JM, Spruijt BM (1999) Isolation during the play period in infancy decreases adult social interactions in rats. Behav Brain Res 100:91-97

Koch M (1999) The neurobiology of startle. Prog Neurobiol 59:107-128

Kurian JR, Bychowski ME, Forbes-Lorman RM, Auger CJ, Auger AP (2008) Mecp2 organizes juvenile social behavior in a sex-specific manner. J Neurosci 28:7137-7142

Leussis MP, Andersen SL (2008) Is adolescence a sensitive period for depression? Behavioral and neuroanatomical findings from a social stress model. Synapse 62:22-30

Leussis MP, Lawson K, Stone K, Andersen SL (2008) The enduring effects of an adolescent social stressor on synaptic density, part II: poststress reversal of synaptic loss in the cortex by adinazolam and MK-801. Synapse 62:185-192

Liu YP, Kao YC, Tung CS (2011) Critical period exists in the effects of isolation rearing on sensorimotor gating function but not locomotor activity in rat. Prog Neuropsychopharmacol Biol Psychiatry 35:1068-1973

Lopes da Silva N, Moraes Ferreira VM, de Padua Carobrez A, Struffaldi Morato G (1996) Individual housing from rearing modifies the performance of young rats on the elevated plusmaze apparatus. Physiol Behav 60:1391-1396

Lukkes J, Vuong S, Scholl J, Olivier H, Forster G (2009a) Corticotropin-releasing factor receptor antagonism within the dorsal raphe nucleus reduces social anxiety-like behavior after earlylife social isolation. J Neurosci 29:9955-9960 
Lukkes JL, Mokin MV, Scholl JL, Forster GL (2009b) Adult rats exposed to early-life social isolation exhibit increased anxiety and conditioned fear behavior, and altered hormonal stress responses. Horm Behav 55:248-256

Lukkes JL, Summers CH, Scholl JL, Renner KJ, Forster GL (2009c) Early life social isolation alters corticotropin-releasing factor responses in adult rats. Neuroscience 158:845-55

Martin P, Caro TM (1985) On the functions of play and its role in behavioral development. Adv Study Behav 15:59-103

Meaney MJ, Stewart J (1981) A descriptive study of social development in the rat (rattus norvegicus). Anim Behav 29:34-45

Meaney MJ, Dodge AM, Beatty WW (1981) Sex-dependent effects of amygdaloid lesions on the social play of prepubertal rats. Physiol Behav 26:467-472

Meng Q, Li N, Han X, Shao F, Wang W (2010) Peri-adolescence isolation rearing alters social behavior and nociception in rats. Neurosci Lett 480:25-29

Panksepp J (1981) The ontogeny of play in rats. Dev Psychobiol 14:327-332

Panksepp J, Beatty WW (1980) Social deprivation and play in rats. Behav Neural Biol 30:197-206

Panksepp J, Siviy SM, Normansell L (1984) The psychobiology of play: theoretical and methodological perspectives. Neurosci Biobehav Rev 8:465-492

Panksepp J, Normansell L, Cox JF, Siviy SM (1994) Effects of neonatal decortication on the social play of juvenile rats. Physiol Behav 56:429-443

Pascual R, Zamora-León SP, Valero-Cabré A (1996) Effects of postweaning social isolation and re-socialization on the expression of vasoactive intestinal peptide (VIP) and dendritic development in the medial prefrontal cortex of the rat. Acta Neurobiol Exp 66:7-14

Peartree NA, Hood LE, Thiel KJ, Sanabria F, Pentkowski NS, Chandler KL, Neisewander JL (2012) Limited physical contact through a mesh barrier is sufficient for social rewardconditioned place preference in adolescent male rats. Physiol Behav 105:749-756

Pellis SM, Pellis VC (1987) Play-fighting differs from serious fighting in both target of attack and tactics of fighting in the laboratory rat Rattus norvegicus. Aggr Behav 13:227-242

Pellis SM, Pellis VC (1990) Differential rates of attack, defense, and counterattack during the developmental decrease in play fighting by male and female rats. Dev Psychobiol 23:215-231

Pellis SM, Pellis VC (1998) Play fighting of rats in comparative perspective: a schema for neurobehavioral analyses. Neurosci Biobehav Rev 23:87-101

Pellis SM, Pellis VC (2009) The playful brain: venturing to the limits of neuroscience. Oneworld Publications, Oxford

Pellis SM, Pellis VC, Dewsbury DA (1989) Different levels of complexity in the play-fighting by muroid rodents appear to result from different levels of intensity of attack and defense. Aggr Behav 15:297-310

Pellis SM, Castañeda E, McKenna MM, Tran-Nguyen LTL, Whishaw IQ (1993) The role of the striatum in organizing sequences of play fighting in neonatally dopamine-depleted rats. Neurosci Lett 158:13-15

Pellis SM, Hastings E, Shimizu T, Kamitakahara H, Komorowska J, Forgie ML, Kolb B (2006) The effects of orbital frontal cortex damage on the modulation of defensive responses by rats in playful and nonplayful social contexts. Behav Neurosci 120:72-84

Pellis SM, Pellis VC, Bell HC (2010) The function of play in the development of the social brain. Am J Play 2:278-296

Poole TB, Fish J (1975) An investigation of playful behavior in Rattus norvegicus and Mus musculus (Mammalia). J Zool Lond 175:61-71

Potegal M, Einon DF (1989) Aggressive behaviors in adult rats deprived of play fighting experience as juveniles. Dev Psychobiol 22:159-172

Robbins TW, Jones GH, Wilkinson LS (1996) Behavioural and neurochemical effects of early social deprivation in the rat. J Psychopharmacol 10:39-47

Robinson DL, Zitzman DL, Smith KJ, Spear LP (2011) Fast dopamine release events in the nucleus accumbens of early adolescent rats. Neuroscience 176:296-307 
Schneider M, Koch M (2005) Deficient social and play behavior in juvenile and adult rats after neonatal cortical lesion: effects of chronic pubertal cannabinoid treatment. Neuropsychopharmacology 30:944-957

Siviy SM (2010) Play and adversity: How the playful mammalian brain withstands threats and anxieties. Am J Play 2:297-314

Siviy SM, Crawford CA, Akopian G, Walsh JP (2011) Dysfunctional play and dopamine physiology in the Fischer 344 rat. Behav Brain Res 220:294-304

Small WS (1899) Notes on the psychic development of the young white rat. Am J Psychol 11:80-100

Smith PK (1982) Does play matter? Functional and evolutionary aspects of animal and human play. Behav Brain Sci 5:139-184

Špinka M, Newberry RC, Bekoff M (2001) Mammalian play: training for the unexpected. Q Rev Biol 76:141-168

Taha SA, Fields HL (2006) Inhibitions of nucleus accumbens neurons encode a gating signal for reward-directed behavior. J Neurosci 26:217-222

Thiel KJ, Okun AC, Neisewander JL (2008) Social reward-conditioned place preference: A model revealing an interaction between cocaine and social context rewards in rats. Drug Alcohol Dep 96:202-212

Thiel KJ, Sanabria F, Neisewander JL (2009) Synergistic interaction between nicotine and social rewards in adolescent male rats. Psychopharmacology 204:391-402

Trezza V, Vanderschuren LJMJ (2008a) Bidirectional cannabinoid modulation of social behavior in adolescent rats. Psychopharmacology 197:217-227

Trezza V, Vanderschuren LJMJ (2008b) Cannabinoid and opioid modulation of social play behavior in adolescent rats: Differential behavioral mechanisms. Eur Neuropsychopharmacol 18:519-530

Trezza V, Damsteegt R, Vanderschuren LJMJ (2009) Conditioned place preference induced by social play behavior: parametrics, extinction, reinstatement and disruption by methylphenidate. Eur Neuropsychopharmacol 19:659-669

Trezza V, Baarendse PJJ, Vanderschuren LJMJ (2010) The pleasures of play: pharmacological insights into social reward mechanisms. Trends Pharmacol Sci 31:463-469

Trezza V, Damsteegt R, Achterberg EJM, Vanderschuren LJMJ (2011) Nucleus accumbens m-opioid receptors mediate social reward. J Neurosci 31:6362-6370

Trezza V, Damsteegt R, Manduca A, Petrosino S, Van Kerkhof LWM, Pasterkamp RJ, Zhou YP, Campolongo P, Cuomo V, Di Marzo V, Vanderschuren LJMJ (2012) Endocannabinoids in amygdala and nucleus accumbens mediate social play reward in adolescent rats. J Neurosci $32: 14899-14908$

Van den Berg CL, Hol T, Van Ree JM, Spruijt BM, Everts H, Koolhaas JM (1999a) Play is indispensable for an adequate development of coping with social challenges in the rat. Dev Psychobiol 34:129-138

Van den Berg CL, Pijlman FTA, Koning HAM, Diergaarde L, Van Ree JM, Spruijt BM (1999b) Isolation changes the incentive value of sucrose and social behaviour in juvenile and adult rats. Behav Brain Res 106:133-142

Van den Berg CL, Van Ree JM, Spruijt BM, Kitchen I (1999c) Effects of juvenile isolation and morphine treatment on social interactions and opioid receptors in adult rats: behavioural and autoradiographic studies. Eur J Neurosci 11:3023-3032

Van den Berg CL, Van Ree JM, Spruijt BM (2000) Morphine attenuates the effects of juvenile isolation in rats. Neuropharmacology 39:969-976

Van Kerkhof LWM, Damsteegt R, Trezza V, Voorn P, Vanderschuren LJMJ (2013a) Functional integrity of the habenula is necessary for social play behaviour in adolescent rats. Eur $\mathrm{J}$ Neurosci 38:3465-3475

Van Kerkhof LWM, Damsteegt R, Trezza V, Voorn P, Vanderschuren LJMJ (2013b) Social play behavior in rats is mediated by functional activity in medial prefrontal cortex and striatum. Neuropsychopharmacology 38:1899-1909 
Van Kerkhof LWM, Trezza V, Mulder T, Gao P, Voorn P, Vanderschuren LJMJ (2013c) Cellular activation in limbic brain systems during social play behaviour in rats. Brain Struct Funct doi: 10.1007/s00429-013-0558-y

Vanderschuren LJMJ, Spruijt BM, Hol T, Niesink RJM, Van Ree JM (1995a) Sequential analysis of social play behavior in juvenile rats: effects of morphine. Behav Brain Res 72:89-95

Vanderschuren LJMJ, Stein EA, Wiegant VM, Van Ree JM (1995b) Social play alters regional brain opioid receptor binding in juvenile rats. Brain Res 680:148-156

Vanderschuren LJMJ, Niesink RJM, Van Ree JM (1997) The neurobiology of social play behavior in rats. Neurosci Biobehav Rev 21:309-326

Von Frijtag JC, Schot M, van den Bos R, Spruijt BM (2002) Individual housing during the play period results in changed responses to and consequences of a psychosocial stress situation in rats. Dev Psychobiol 41:58-69

Whitaker LR, Degoulet M, Morikawa H (2013) Social deprivation enhances VTA synaptic plasticity and drug-induced contextual learning. Neuron 77:335-345

Wright IK, Upton N, Marsden CA (1991) Resocialisation of isolation-reared rats does not alter their anxiogenic profile on the elevated X-maze model of anxiety. Physiol Behav 50:129-1132

Zeeb FD, Robbins TW, Winstanley CA (2009) Serotonergic and dopaminergic modulation of gambling behavior as assessed using a novel rat gambling task. Neuropsychopharmacology 34:2329-2343 